\title{
High prevalence of smoking in patients with adrenal incidentalomas: causality or case selection?
}

\author{
Henrik Olsen 1,2, Albin Kjellbom ${ }^{1,2}$, Magnus Löndahl ${ }^{1,2}$ and Ola Lindgren ${ }^{1,2}$ \\ ${ }^{1}$ Department of Endocrinology, Skane University Hospital, Lund, Sweden and ${ }^{2}$ Department of Clinical Sciences Lund, \\ Endocrinology, Faculty of Medicine, Lund University, Lund, Sweden
}

Correspondence should be addressed to $\mathrm{H}$ Olsen

Email

henrik.olsen@med.lu.se

\begin{abstract}
Objective: Autonomous cortisol secretion and possible autonomous cortisol secretion (ACS/pACS) are associated to an increase of cardiovascular risk factors such as hypertension, diabetes mellitus and dyslipidaemia. To our knowledge, the prevalence of smoking, another well-established risk factor for cardiovascular disease, has not been studied in detail in people with ACS/pACS or adrenal incidentalomas.

Methods: Patients with adrenal incidentalomas were examined with the 1-mg overnight dexamethasone suppression

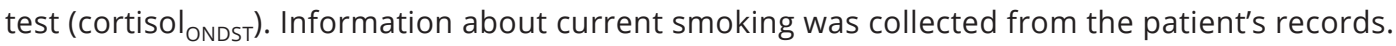

Results: We studied 1044 patients, of whom 370 (35\%) were current smokers. Of these, 22\% had bilateral Al compared to $12 \%$ of the non-smokers $(P<0.001)$. Among patients with unilateral adrenal incidentalomas, smokers had larger adrenal incidentalomas than non-smokers (22 mm vs $19 \mathrm{~mm}, P<0.001)$. Smokers also more often had cortisol ONDST $\geq 50 \mathrm{nmol} / \mathrm{L}$ than non-smokers, $54 \%$ vs $40 \%(P<0.001)$, a finding independent of the size of the adrenal incidentaloma in patients with unilateral adrenal incidentalomas.

Conclusions: In the present study of patients with adrenal incidentalomas, the prevalence of current smoking was higher than in the general population. Furthermore, smokers had larger unilateral adrenal incidentalomas, more often bilateral adrenal incidentalomas, and more frequently ACS/pACS. Whether smoking is a risk factor for adrenal incidentalomas and ACS/pACS or our findings are due to case selection needs to be further studied.
\end{abstract}

\section{Introduction}

Adrenal incidentalomas are frequently found at imaging examinations and may cause autonomous cortisol secretion (ACS) and possible autonomous cortisol secretion (pACS) (1). ACS/pACS has been linked to increased cardiovascular morbidity and mortality $(2,3,4)$. Furthermore, ACS/pACS is associated with increased cancer mortality (5) as opposed to overt Cushing syndrome (6). The reason for this difference is not known, although selection bias might be involved. Smoking is an important risk factor for both cancer and cardiovascular disease, but smoking habits among patients with adrenal incidentalomas have not been comprehensively investigated. Our aim was, therefore, to study the prevalence of smoking in relation to morphology and cortisol secretion in a large consecutive geographically well-defined group of patients with adrenal incidentalomas.

\section{Methods}

Patients examined for adrenal incidentalomas at Helsingborg Hospital and the departments in Malmö and Lund of Skane University Hospital between January 1, 2005 and September 15, 2015 were included in the

Published by Bioscientifica Ltd. 
absence of one or more of the following exclusion criteria: presence of a metastatic malignancy; adrenal incidentalomas smaller than $1 \mathrm{~cm}$; non-adenoma lesions such as myelolipomas, haemorrhages and cysts; biochemical results supporting pheochromocytoma, primary hyperaldosteronism, or clinical Cushing's syndrome; oral corticoid treatment more than single doses in the past 3 months; use of inhalation steroids or medication affecting dexamethasone metabolism and systemic oestrogen treatment. Medical history was collected from patient records. Current smokers were defined as daily smokers and thus did not include occasional smokers. Data on previous smoking was not collected as this was not available in most records. All patients were examined with the 1-mg overnight dexamethasone suppression test ( cortisol $_{\text {ONDST }}$ ). Basal ACTH was collected in the majority of the patients. The size of the adrenal incidentalomas was defined as the maximal axial diameter and adrenal incidentalomas considered bilateral in patients with a lesion with the minimal size of $1 \mathrm{~cm}$ in both adrenal glands. The CT scans were evaluated by the clinical radiologists and confirmed by two of the authors (A K, H O). The study was approved by the Ethics Committee, Lund, Sweden. Informed consent was not required due to the nature of the study.

\section{Laboratory analyses}

Plasma cortisol was analysed using a one-step competitive immunoassay (Roche Diagnostics). The reference range was (171-536 $\mathrm{nmol} / \mathrm{L})$, the coefficient of variation (CV) $2.1 \%$ at $94.9 \mathrm{nmol} / \mathrm{L}$, and the detection limit 0.5 nmol/L. Plasma ACTH was analysed using two twostep immunometric sandwich assays (Cobas $\left.{ }^{\circledR}\right)$, Roche Diagnostics and Nichols Institute Diagnostics, CA, USA). The reference range for Roche assay was $1.6-13.9 \mathrm{pmol} / \mathrm{L}$, the CV $5.4 \%$ at $1.1 \mathrm{pmol} / \mathrm{L}$, and the detection limit 0.23 $\mathrm{pmol} / \mathrm{L}$, and $2.0-10.0 \mathrm{pmol} / \mathrm{L}, 9 \%$ at $8.0 \mathrm{pmol} / \mathrm{L}$, and 2.0 $\mathrm{pmol} / \mathrm{L}$, respectively for the Nichols Institute Diagnostics assay. The latter was used in the department in Malmö from the start of the study period until 20/2/2012.

\section{Data analyses}

Results for ACTH achieved with the assay from Nichols Institute Diagnostics was only used to separate patients into groups with $\mathrm{ACTH}<2.0 \mathrm{pmol} / \mathrm{L}$ or $\geq 2.0 \mathrm{pmol} / \mathrm{L}$ because of the low precision.

\section{Statistical analyses}

The statistical analysis was performed using PASW statistics 25 (SPSS Inc.). Results are expressed as medians and ranges. Comparisons of categorical data between groups were made using Chi-squared test or Fisher's exact test as appropriate and comparisons of continuous data between groups with the Mann-Whitney $U$-test. Multivariable logistic regression was used to study the prevalence of cortisol $_{\text {ONDST }} \geq 50 \mathrm{nmol} / \mathrm{L}$ according to whether the adrenal incidentaloma was unilateral or bilateral and whether the patient was a smoker or non-smoker, adjusted for age. The same analysis was also performed with the patients grouped by gender and into four age groups. Confidence intervals for binomial data were calculated with the Clopper-Pearson test. Multivariable logistic regression was used among patients with unilateral AI to study the prevalence of cortisol $_{\text {ONDST }} \geq 50 \mathrm{nmol} / \mathrm{L}$ in smokers vs non-smokers, adjusted for gender, age, BMI, and size of the adrenal incidentaloma. Multivariable logistic regression was also used among patients with unilateral adrenal incidentaloma to study the prevalence of ACTH $<2.0 \mathrm{pmol} / \mathrm{L}$ in smokers vs non-smokers, adjusted for gender, age, BMI, size of the adrenal incidentaloma, and cortisol $_{\text {ONDST }}$. Cortisol ${ }_{\text {ONDST }}$ was in-transformed in this analysis. To study whether the total smoking exposure is associated to whether the adrenal incidentalomas was bilateral, cortisol ${ }_{\mathrm{ONDST}}$, and the size of the unilateral incidentalomas, these three factors were studied in smoker and non-smokers separately. Univariable logistic regression was used to study the relation between age and whether the adrenal incidentaloma was unilateral or bilateral and whether cortisol $_{\text {ONDST }}$ was $<50$ or $\geq 50$ $\mathrm{nmol} / \mathrm{L}$ in smokers and non-smokers. Univariable linear regression was used to study the relation between age and size of the unilateral adrenal incidentaloma in smokers and non-smokers. A $P$-value $<0.05$ was considered to indicate statistically significant differences.

\section{Results}

We screened 1594 patients consecutively examined for adrenal incidentalomas, and of these 550 were excluded based on the exclusion criteria, and thus, 1044 patients were included, of which 370 (35\%) were current smokers. The prevalence of smoking declined during the study period in males from 41\% (38 of 93) during 2005-2008 to $25 \%$ (36 of 145 ) during 2013-2015 $(P=0.009)$, but was unchanged in women, 35\% (43 of 124) and 39\% 
(86 of 222) $(P=0.45)$, respectively. Smokers were younger, had lower BMI, more often bilateral adrenal incidentalomas, larger unilateral adrenal incidentalomas, lower ACTH and higher cortisol ${ }_{\text {ONDST }}$ than non-smokers, although the prevalence's of treated hypertension, diabetes mellitus, and dyslipidaemia were lower among smokers. Patient's characteristics are given in Table 1. Of the patients with bilateral adrenal incidentalomas, three or more nodules were present in 22 patients and of these 7 were smokers. The indications for the imaging examinations are given in Table 2 .

The prevalence of cortisol $_{\mathrm{ONDST}} \geq 50 \mathrm{nmol} / \mathrm{L}$ in smokers and non-smokers with unilateral or bilateral adrenal incidentalomas are given in Fig. 1. The prevalence of cortisol $_{\text {ONDST }} \geq 50 \mathrm{nmol} / \mathrm{L}$ was increased in smokers in both unilateral and bilateral adrenal incidentalomas. Table 3 gives the prevalence of smoking according to gender and age group in the background population as reported by Ali et al. (7) and in patients divided into groups whether they had unilateral or bilateral adrenal incidentalomas and whether they had cortisol $_{\text {ONDST }}<50 \mathrm{nmol} / \mathrm{L}$ or cortisol $_{\text {ONDST }} \geq 50 \mathrm{nmol} / \mathrm{L}$. In multivariable analysis, the risk of having bilateral adrenal incidentalomas was higher in smokers (OR: 2.1, $P<0.0001$ ) and increased with age (OR: 1.2 for 10 years increase in age, $P=0.03$ ) but was independent of gender. Among patients with unilateral adrenal incidentalomas, the relations of smoking to ACTH $<2.0 \mathrm{pmol} / \mathrm{L}$ and cortisol $_{\text {ONDST }} \geq 50 \mathrm{nmol} / \mathrm{L}$, adjusted for gender, age, the size of the $\mathrm{AI}$, and $\mathrm{BMI}$, are given in Table 4.

The probability of harbouring bilateral adrenal incidentalomas increased with age in smokers (32\% increase per 10 years increase, $P=0.03$ ) but was not related to age in non-smokers ( $11 \%$ increase per 10 years increase, $P=0.37)$. The size of the adrenal incidentaloma in patients with unilateral adrenal incidentalomas was independent of age in both smokers $(-0.07 \mathrm{~mm}$ per 10 years increase, $P=0.89$ ) and non-smokers ( $0.09 \mathrm{~mm}$ per 10 years increase, $P=0.76)$. The prevalence of cortisol $_{\text {ONDST }} \geq 50 \mathrm{nmol} / \mathrm{L}$ increased with age in both smokers $(71 \%$ increase per 10 years, $(P<0.0001)$ and non-smokers $(78 \%$ increase per 10 years, $P<0.0001)$.

\section{Missing data}

Basal ACTH was measured with the Roche and Nichols methods in 576 and 185 patients, respectively, and was thus not available in 283 patients.

\section{Discussion}

The frequency of current smokers in our population varied with gender, age and time of enrolment in a similar pattern as in the general population $(7,8)$. In the study by Ali et al., 27963 persons living in our county (Skåne), randomly selected from the population registry, answered a postal questionnaire (7). The subjects categorized themselves into one of the four categories: daily smoker, intermittent (non-daily) smoker, stopped smoking and never smoked. The prevalence of smoking among our patients with unilateral adrenal incidentalomas was approximately twice and among patients with bilateral adrenal incidentalomas approximately three times that reported by Ali et al. (7). For instance, in our female patients between 55 and 64 years of age, the smoking prevalence

Table 1 Characteristics of all patients and patients divided into two groups according to whether they were current smokers or non-smokers.

\begin{tabular}{l}
\hline$n$ \\
Gender (\% females) \\
Age (years) \\
BMI (kg/m²) \\
Bilateral (\%) \\
Size of the unilateral Al (mm) \\
Cortisol (nmol/L) \\
ACTH* (pmol/L) \\
Cortisol \\
Cortisol $(\mathrm{nmDS}$ ONDS $\geq 50$ (\%) \\
Treatment for hypertension (\%) \\
Diabetes mellitus (\%) \\
Treatment for dyslipidaemia (\%)
\end{tabular}

\begin{tabular}{c}
\hline All patients \\
\hline 1044 \\
59 \\
$64.8(24.4-88.7)$ \\
$27.4(12.8-55.2)$ \\
16 \\
$20(10-72)$ \\
$473(131-1299)$ \\
$3.1(<0.23-26.0)$ \\
$46(9-487)$ \\
45 \\
52 \\
19 \\
31
\end{tabular}

\begin{tabular}{c}
\hline Non-smokers \\
\hline 674 \\
56 \\
$66.3(24.4-88.7)$ \\
$28.1(12.8-50.4)$ \\
12 \\
$19(10-70)$ \\
$473(131-1299)$ \\
$3.7(<0.23-26.0)$ \\
$43(9-487)$ \\
40 \\
57 \\
21 \\
35
\end{tabular}

\begin{tabular}{c}
\hline Smokers \\
\hline 370 \\
64 \\
$61.5(24.7-88.2)$ \\
$26.5(15.0-55.2)$ \\
22 \\
$22(10-72)$ \\
$472(157-1244)$ \\
$2.0(<0.23-11.0)$ \\
$53(11-449)$ \\
54 \\
44 \\
15 \\
23
\end{tabular}

\begin{tabular}{c}
\hline $\boldsymbol{P}$ \\
\hline \\
0.009 \\
$<0.0001$ \\
$<0.0001$ \\
0.0001 \\
0.0002 \\
0.81 \\
$<0.0001$ \\
$<0.0001$ \\
$<0.0001$ \\
$<0.0001$ \\
0.017 \\
$<0.0001$
\end{tabular}

*ACTH levels measured with the method with best accuracy (Roche method) was available in 576 (55\%) of the patients.

$P$-values are significance level for smokers compared to non-smokers. 
Table 2 Indications for imaging stratified by smoking status.

\begin{tabular}{l} 
Indications for the imaging examinations \\
\hline Abdominal pain including pain in the side (\%) \\
Cancer including examining for suspected cancer (\%) \\
Chest pain and dyspnoea (\%) \\
Gl bleeding (\%) \\
Haematuria (\%) \\
Trauma (\%) \\
Aortic aneurysm including examination for suspected aneurysm (\%) \\
Study (\%) \\
Other indications (\%) \\
Not available (\%) \\
Total
\end{tabular}

\begin{tabular}{c}
\hline All patients \\
\hline $487(47)$ \\
$97(9)$ \\
$78(7)$ \\
$24(2)$ \\
$54(5)$ \\
$38(4)$ \\
$23(2)$ \\
$4(0)$ \\
$234(22)$ \\
$5(0)$ \\
1044
\end{tabular}

\begin{tabular}{c}
\hline Non-smokers \\
\hline $319(47)$ \\
$64(9)$ \\
$56(8)$ \\
$15(2)$ \\
$36(5)$ \\
$24(4)$ \\
$16(2)$ \\
$3(0)$ \\
$138(20)$ \\
$3(0)$ \\
674 \\
\hline
\end{tabular}

\begin{tabular}{c}
\hline Smokers \\
\hline $168(45)$ \\
$33(9)$ \\
$22(6)$ \\
$9(2)$ \\
$18(5)$ \\
$14(4)$ \\
$7(2)$ \\
$1(0)$ \\
$96(26)$ \\
$2(1)$ \\
370
\end{tabular}

was $42 \%$ in people with unilateral adrenal incidentalomas and $57 \%$ in those with bilateral adrenal incidentalomas as compared to $20 \%$ in the cited study (7). Corresponding data for men at the same age were 28,55 , and $19 \%$, respectively (7). Current smoking, thus, seems to be more prevalent in our patients than in the general population, independent of gender and age. In our study, smokers

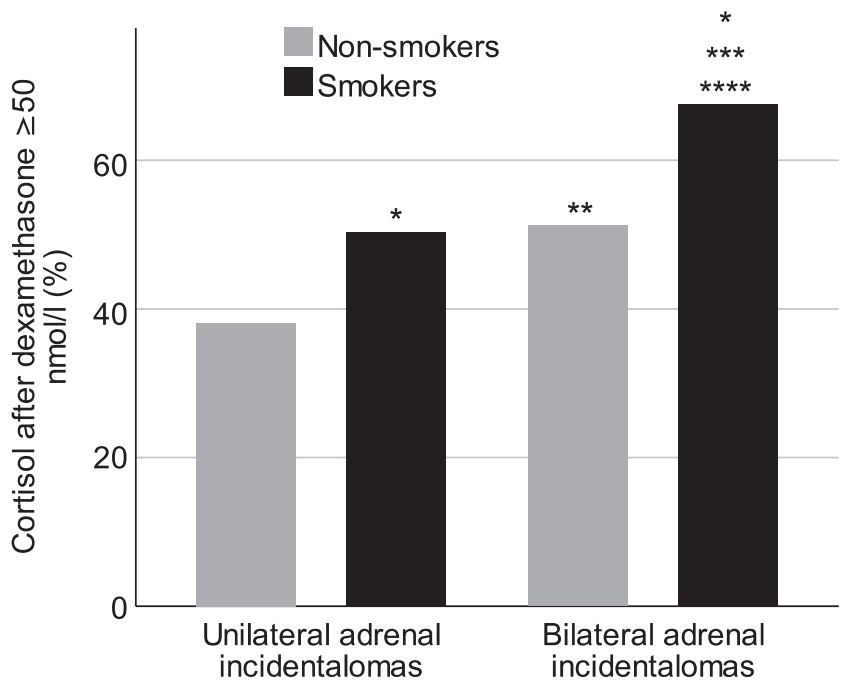

\section{Figure 1}

The prevalence's of cortisol ONDST $\geq 50 \mathrm{nmol} / \mathrm{L}$ in patients divided into four groups according to whether they had unilateral or bilateral adrenal incidentalomas and whether they were smokers or non-smokers. ${ }^{*} P<0.0001$ compared to non-smokers with unilateral adrenal incidentaloma, adjusted for age. ${ }^{*} P=0.033$ compared to non-smokers with unilateral adrenal incidentaloma, adjusted for age. ${ }^{*} * P=0.027$ compared to non-smokers with unilateral adrenal incidentaloma, adjusted for age. $* \star \star \star P=0.009$ compared to non-smokers with bilateral adrenal incidentalomas, adjusted for age. The prevalence of cortisol ${ }_{\text {ONDST }} \geq 50 \mathrm{nmol} / \mathrm{L}$ was increased in smokers independently of whether the adrenal incidentaloma was unilateral or bilateral. had bilateral adrenal incidentalomas approximately twice as often as non-smokers, a finding comparable to that previously described by Hao et al. (9). Further, in people with unilateral adrenal incidentalomas, the tumours were larger among smokers. Smoking habits were also linked to cortisol $_{\text {ONDST }}$ with smokers having cortisol $_{\text {ONDST }} \geq 50$ nmol/L more often, both among patients with unilateral and bilateral adrenal incidentalomas. We have identified six studies that have reported the prevalence of smoking in patients with or without ACS/pACS $(10,11,12,13,14$, 15). Only two of these reported an increased prevalence of smoking among patients with ACS/pACS $(14,15)$. However, all these studies were considerably smaller than ours and differences in smoking habits between groups were not adjusted for plausible confounding factors such as gender and age. We had not the possibility to separate former smokers from never smokers. The differences in the prevalence of bilateral adrenal incidentalomas, the size of the unilateral AI and the prevalence's of cortisol ${ }_{\mathrm{ONDST}}$ $\geq 50 \mathrm{nmol} / \mathrm{L}$ between smokers and never smokers may therefore be larger than the reported differences between smokers and non-smokers. It could be suspected that the increased prevalence of ACS/pACS found in smokers could be explained by an activation of the HPA-axis, but the lower ACTH found in smokers contradicts this.

We can only speculate whether the relation between smoking and adrenal incidentalomas may be causal or not. Smoking has chronologically the possibility to be causal to an adrenal incidentaloma (16) and smoking has been linked to colorectal adenomas and Warthin's tumours in the salivary glands and among the endocrine glands to thyroid nodules and functional ovarian cysts (17, 18, 19, 20). The very high prevalence of smokers among patients with adrenal incidentalomas was further increased among patients with ACS/pACS, suggesting that smoking may be a causal factor for adrenal incidentalomas and ACS/ pACS. The lack of data on duration of smoking, number of cigarettes smoked daily and former smokers hampers 


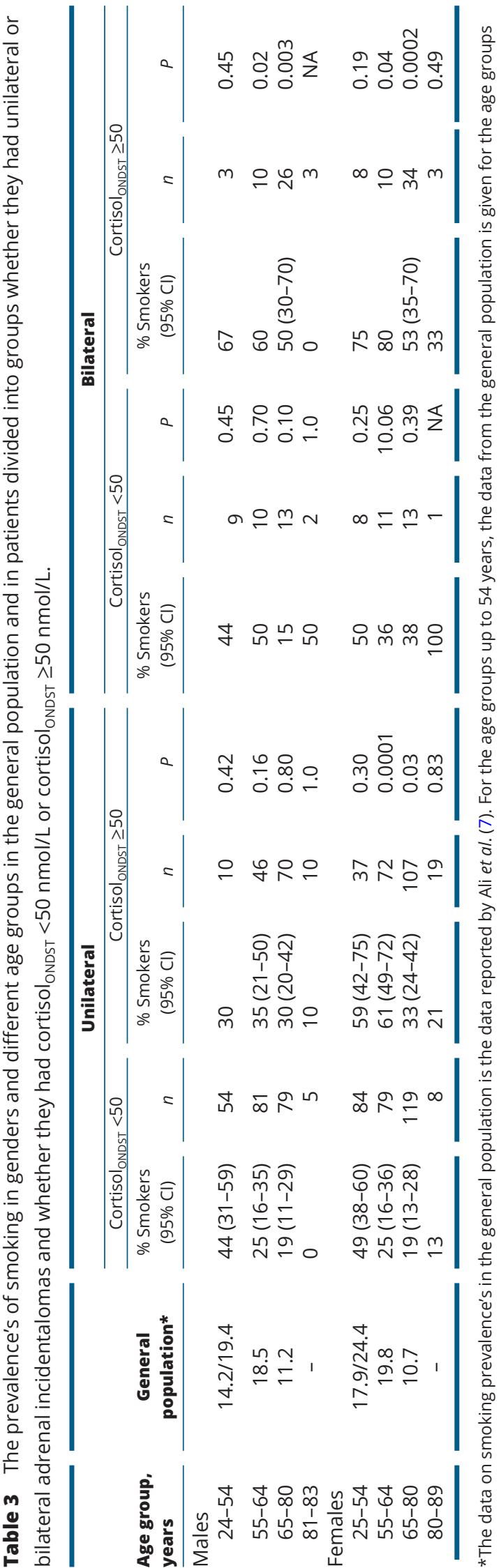

the possibility to relate the total smoking volume of each patient to their adrenal incidentaloma and cortisol $_{\text {ONDST }}$. However, people usually start smoking as adolescents or young adults as reported by Douglas et al. who found that the median age for smoke initiation was 19 years and that initiation of smoking after the age of 24 years was rare (21). The duration of smoking is thus strongly correlated to the age of the patients. The presence of bilateral adrenal incidentalomas increased with age in smokers but not in non-smokers, which thus indicates that the total load of smoking may be of importance. On the contrary, we found no differences in the relations of age to the size of unilateral adrenal incidentalomas or cortisol $_{\text {ONDST }} \geq 50 \mathrm{nmol} / \mathrm{L}$ between smokers and non-smokers to further support this. However, the low proportion of smokers below 50 years of age corresponding to a duration of smoking below 30 years may limit the possibility to detect this. An explanation for the increased prevalence of cortisol $_{\text {ONDST }} \geq 50 \mathrm{nmol} / \mathrm{L}$ in smokers may be an effect of smoking on dexamethasone metabolism, but two earlier studies reported no effect of smoking on the dexamethasone levels $(15,22)$. The relation between AI and smoking may alternatively be non-causal. An adrenal incidentaloma is defined as an adrenal enlargement detected at an imaging examination performed for another indication than a suspected adrenal disease. Smoking is linked to increased morbidity in general, which might lead to a higher frequency of imaging examinations in smokers, plausibly leading to an increased detection rate in smokers harbouring an AI. Increased smoking habits may also explain the increased incidence cardiovascular risk factors in patients with an adrenal incidentaloma considered to be non-functional (12). A selection bias due to hormone levels may also occur. This is possible if the coexistence of the two risk factors, hormonal alterations, and smoking enhance the risk for disease not simply additively but synergistically, which is the case for other cardiovascular risk factors (23). Thus, the detection rate may be increased due to high morbidity in smokers with ACS/pACS. As smoking is a well-known risk factor for cancer, our data may also explain the somewhat unexpected finding of malignancy being the cause of increased mortality in patients with ACS in one study (5).

Although, our observations are strengthened by our large study population and the high validity of the variables studied, several limitations, including its crosssectional design, provide no possibility to study causality. As previously discussed, data on former smokers, duration of smoking, amount of daily smoking in smokers and the use of snuff tobacco were not available. 
Table 4 Multivariable logistic regression for whether cortisol $_{\text {ONDST }}$ was $<50 \mathrm{nmol} / \mathrm{L}$ or $\geq 50 \mathrm{nmol} / \mathrm{L}$ and whether $\mathrm{ACTH}$ was $\geq 2.0 \mathrm{pmol} / \mathrm{L}$ or $<2.0 \mathrm{pmol} / \mathrm{L}$ in patients with unilateral adrenal incidentalomas.

\begin{tabular}{|c|c|c|}
\hline & $\begin{array}{l}\text { OR for cortisol }{ }_{\text {ONDST }} \\
\quad \geq 50 \mathrm{nmol} / \mathrm{L}\end{array}$ & $\begin{array}{l}\text { OR for ACTH } \\
<2.0 \mathrm{pmol} / \mathrm{L}\end{array}$ \\
\hline $\begin{array}{l}\text { Gender } \\
\quad \text { (female vs male) }\end{array}$ & $1.32(0.98-1.78)$ & $2.19(1.41-3.41)$ \\
\hline Age (10-year increase) & 1.69 (1.46-1.96) & $0.87(0.72-1.06)$ \\
\hline Smoker (yes vs no) & $1.68(1.21-2.33)$ & $2.75(1.80-4.20)$ \\
\hline BMI (increase $5 \mathrm{~kg} / \mathrm{m}^{2}$ ) & $0.80(0.69-0.91)$ & $0.99(0.83-1.18)$ \\
\hline Size (increase 10 mm) & $1.85(1.52-2.22)$ & $1.55(1.22-1.95)$ \\
\hline $\begin{array}{l}\text { Cortisol } \\
\quad \text { (increast } \\
\quad 100 \%)\end{array}$ & Not analysed & $2.01(1.55-2.61)$ \\
\hline
\end{tabular}

The number of patients included in the analysis of the OR for cortisol ONDST $\geq 50 \mathrm{nmol} / \mathrm{L}$ and the $\mathrm{OR}$ for ACTH $<2.0 \mathrm{pmol} / \mathrm{L}$ are 861 and 638 , respectively.

In summary, in the present population-based study, the prevalence of current smoking was higher than in the general population. Furthermore, smokers had larger unilateral AI, more often bilateral AI and ACS/ pACS. Whether smoking is a risk factor for adrenal incidentalomas and ACS/pACS or our findings are due to case selection needs to be further studied.

\section{Declaration of interest}

The authors declare that there is no conflict of interest that could be perceived as prejudicing the impartiality of the research reported.

\section{Funding}

None

\section{References}

1 Fassnacht M, Arlt W, Bancos I, Dralle H, Newell-Price J, Sahdev A, Tabarin A, Terzolo M, Tsagarakis S \& Dekkers OM. Management of adrenal incidentalomas: European society of endocrinology clinical practice guideline in collaboration with the European network for the study of adrenal tumors. European Journal of Endocrinology 2016 175 G1-G34. (https://doi.org/10.1530/EJE-16-0467)

2 Debono M, Bradburn M, Bull M, Harrison B, Ross RJ \& NewellPrice J. Cortisol as a marker for increased mortality in patients with incidental adrenocortical adenomas. Journal of Clinical Endocrinology \& Metabolism 201499 4462-4470. (https://doi.org/10.1210/jc.20143007)

3 Di Dalmazi G, Vicennati V, Garelli S, Casadio E, Rinaldi E, Giampalma E, Mosconi C, Golfieri R, Paccapelo A, Pagotto U, et al. Cardiovascular events and mortality in patients with adrenal incidentalomas that are either non-secreting or associated with intermediate phenotype or subclinical Cushing's syndrome: a 15-year retrospective study. Lancet: Diabetes \& Endocrinology 20142 396-405. (https://doi.org/10.1016/S2213-8587(13)70211-0)

4 Morelli V, Reimondo G, Giordano R, Della Casa S, Policola C, Palmieri S, Salcuni AS, Dolci A, Mendola M, Arosio M, et al. Long- term follow-up in adrenal incidentalomas: an Italian multicenter study. Journal of Clinical Endocrinology \& Metabolism 201499 827-834. (https://doi.org/10.1210/jc.2013-3527)

5 Patrova J, Kjellman M, Wahrenberg H \& Falhammar H. Increased mortality in patients with adrenal incidentalomas and autonomous cortisol secretion: a 13-year retrospective study from one center. Endocrine 201758 267-275. (https://doi.org/10.1007/s12020-0171400-8)

6 Ntali G, Asimakopoulou A, Siamatras T, Komninos J, Vassiliadi D, Tzanela M, Tsagarakis S, Grossman AB, Wass JA \& Karavitaki N. Mortality in Cushing's syndrome: systematic analysis of a large series with prolonged follow-up. European Journal of Endocrinology 2013169 715-723. (https://doi.org/10.1530/EJE-13-0569)

7 Ali SM, Chaix B, Merlo J, Rosvall M, Wamala S \& Lindström M. Gender differences in daily smoking prevalence in different age strata: a population-based study in southern Sweden. Scandinavian Journal of Public Health 200937 146-152. (https://doi. org/10.1177/1403494808100274)

8 Norberg M, Lundqvist G, Nilsson M, Gilljam H \& Weinehall L. Changing patterns of tobacco use in a middle-aged population: the role of snus, gender, age, and education. Global Health Action 20114 5613. (https://doi.org/10.3402/gha.v4i0.5613)

9 Hao M, Lopez D, Luque-Fernandez MA, Cote K, Newfield J, Connors M \& Vaidya A. The lateralizing asymmetry of adrenal adenomas. Journal of the Endocrine Society 20182 374-385. (https:// doi.org/10.1210/js.2018-00034)

10 Morelli V, Palmieri S, Lania A, Tresoldi A, Corbetta S, Cairoli E, Eller-Vainicher C, Arosio M, Copetti M, Grossi E, et al. Cardiovascular events in patients with mild autonomous cortisol secretion: analysis with artificial neural networks. European Journal of Endocrinology 2017177 73-83. (https://doi.org/10.1530/EJE-170047)

11 Di Dalmazi G, Vicennati V, Rinaldi E, Morselli-Labate AM, Giampalma E, Mosconi C, Pagotto U \& Pasquali R. Progressively increased patterns of subclinical cortisol hypersecretion in adrenal incidentalomas differently predict major metabolic and cardiovascular outcomes: a large cross-sectional study. European Journal of Endocrinology 2012166 669-677. (https://doi.org/10.1530/ EJE-11-1039)

12 Androulakis II, Kaltsas GA, Kollias GE, Markou AC, Gouli AK, Thomas DA, Alexandraki KI, Papamichael CM, Hadjidakis DJ \& Piaditis GP. Patients with apparently nonfunctioning adrenal incidentalomas may be at increased cardiovascular risk due to excessive cortisol secretion. Journal of Clinical Endocrinology \& Metabolism 201499 2754-2762. (https://doi.org/10.1210/jc.20134064)

13 Terzolo M, Bovio S, Pia A, Conton PA, Reimondo G, Dall'Asta C, Bemporad D, Angeli A, Opocher G, Mannelli M, et al. Midnight serum cortisol as a marker of increased cardiovascular risk in patients with a clinically inapparent adrenal adenoma. European Journal of Endocrinology 2005153 307-315. (https://doi.org/10.1530/ eje.1.01959)

14 Di Dalmazi G, Fanelli F, Zavatta G, Ricci Bitti S, Mezzullo M, Repaci A, Pelusi C, Gambineri A, Altieri P, Mosconi C, et al. The steroid profile of adrenal incidentalomas: subtyping subjects With high cardiovascular risk. Journal of Clinical Endocrinology \& Metabolism 2019104 5519-5528. (https://doi.org/10.1210/jc.2019-00365)

15 Ueland GÅ, Methlie P, Kellmann R, Bjørgaas M, Åsvold BO, Thorstensen K, Kelp O, Thordarson HB, Mellgren G, Løvås K, et al. Simultaneous assay of cortisol and dexamethasone improved diagnostic accuracy of the dexamethasone suppression test. European Journal of Endocrinology 2017176 705-713. (https://doi.org/10.1530/ EJE-17-0078)

16 Bovio S, Cataldi A, Reimondo G, Sperone P, Novello S, Berruti A, Borasio P, Fava C, Dogliotti L, Scagliotti GV, et al. Prevalence of adrenal incidentaloma in a contemporary computerized tomography 
series. Journal of Endocrinological Investigation 200629 298-302. (https://doi.org/10.1007/BF03344099)

17 Bailie L, Loughrey MB \& Coleman HG. Lifestyle risk factors for serrated colorectal polyps: a systematic review and meta-analysis. Gastroenterology 2017152 92-104. (https://doi.org/10.1053/j.gastro.2016.09.003)

18 Kim SY, Min C, Oh DJ \& Choi HG. Tobacco smoking and alcohol consumption are related to benign parotid tumor: A nested casecontrol study using a national health screening cohort. Clinical \& Experimental Otorhinolaryngology 201912 412-419. (https://doi. org/10.21053/ceo.2018.01774)

19 Holt VL, Cushing-Haugen KL \& Daling JR. Risk of functional ovarian cyst: effects of smoking and marijuana use according to body mass index. American Journal of Epidemiology 2005161 520-525. (https:// doi.org/10.1093/aje/kwi080)

20 Galanti MR, Granath F, Cnattingius S, Ekbom-Schnell A \& Ekbom A. Cigarette smoking and the risk of goitre and thyroid nodules amongst parous women. Journal of Internal Medicine 2005258 257-264. (https://doi.org/10.1111/j.1365-2796.2005.01523.x)

21 Douglas S \& Hariharan G. The hazard of starting smoking: estimates from a split population duration model. Journal of Health Economics 199413 213-230. (https://doi.org/10.1016/0167-6296(94)90024-8)

22 Ceccato F, Artusi C, Barbot M, Lizzul L, Pinelli S, Costantini G, Niero S, Antonelli G, Plebani M \& Scaroni C. Dexamethasone measurement during low-dose suppression test for suspected hypercortisolism: threshold development with and validation. Journal of Endocrinological Investigation 2020 [Online ahead of print]. (https://doi.org/10.1007/s40618-020-01197-6)

23 Conroy RM, Pyörälä K, Fitzgerald AP, Sans S, Menotti A, De Backer G, De Bacquer D, Ducimetière $\mathrm{P}$, Jousilahti $\mathrm{P}$, Keil $\mathrm{U}$, et al. Estimation of ten-year risk of fatal cardiovascular disease in Europe: the SCORE project. European Heart Journal 200324 987-1003. (doi:10.1016/ s0195-668x(03)00114-3)

Received 24 January 2020

Revised version received 11 June 2020

Accepted 29 June 2020 